\title{
A cultura da nostalgia como aspecto da mercantilização do futebol
}

The culture of nostalgia as an aspect of the commodification of football

La cultura de la nostalgia como um aspect de la comercialización del fútbol

Tatiane Hilgemberg - Universidade Federal de Roraima | Boa Vista | RR | Brasil | tatianehilgemberg@gmail.com | https//orcid.org/0000-0003-2112-0944

Marcos Henrique Martins Marques - Universidade Federal de Roraima | Boa Vista | RR | Brasil | mhmartins88@gmail.com | https://orcid.org/0000-0002-23571354

Resumo: Para atrair consumidores uma mercadoria precisa agregar valores simbólicos e assim adquirir algum apelo de novidade. Dentro deste contexto é perceptível a popularização de produtos da indústria do entretenimento que trazem referências históricas com o objetivo de utilizar os sentimentos de nostalgia das pessoas. Este artigo busca identificar, através do método qualitativo exploratório, como os elementos do passado e os sentimentos nostálgicos são utilizados em quatro produtos (duas camisas de futebol e duas campanhas publicitárias) voltados para torcedores de dois clubes do futebol brasileiro. Percebemos que a espetacularização do futebol possui relação íntima com esta indústria e tem transformado o esporte e tudo que gira ao seu redor não ficando alheio a esse fenômeno nostálgico.

Palavras-chave: Consumo. Mídia. Futebol brasileiro. Nostalgia.

Abstract: In order to attract consumers a commodity needs to add symbolic values and thus acquire some appeal for novelty. Within this context it is perceptible to the popularization of products of the entertainment industry that bring historical references with the objective of using the feelings of nostalgia of people. Thus this article seeks to identify, using qualitative exploratory method, how the elements of the past are used in four products (two soccer shirts and two advertising campaigns) aimed at fans of two Brazilian soccer clubs. In this sense the spetacularization of soccer has an intimate relation with this industry and has changed sport and everything around it, that does not go far from the nostalgic phenomenon.

Key words: Consume. Media. Brazilian football. Nostalgia.

Resumen: Para atraer a los conumidores, una mercancía necessita agregar valores cimbóicos y así adquirir um atractivo novedoso. Em este contexto, es notable la popularización de produtos de la indústria del entretenimento que aportan referencias históricas para utilizar los sentimentos de nostalgia de las personas. Este artículo busca identificar, a través del método de exploración cualitativa, como se utilizan los elementos del passado y los sentimentos nostálgicos em cuatro produtos (dos camisetas e fútbol y dos campañas piblicitarias) dirigidos a los fanáticos de dos clubes de fútbol brasileños. Nos dimos cuenta de que la espetacularización del fútbol tiene uma relación íntima com esta indústria y há transformado el deporte y todo lo que gira a su alredodor, sin ser ajeno a este fenómeno nostálgico.

Palabras clave: Consumo. Medios de comunicación. Fútbol brasileño. Nostalgia. 


\section{Introdução}

Para ser vista como diferenciada uma mercadoria precisa vender valores, pois o consumidor deseja adquirir um produto com o qual possa se expressar, e que evoque experiências e associações. As transformações nos valores sociais e padrões de consumo de nossa sociedade proporcionaram a chegada do consumo simbólico, no qual os objetos passam a ser valorizados pelos significados atribuídos. Assim, percebemos que sentidos, desejos e a necessidade de reafirmar status e pertença a uma identidade são acrescidos à capacidade dos objetos de desempenharem uma determinada função.

$\mathrm{Na}$ contemporaneidade percebe-se que a nostalgia tem ganhado função simbólica para a venda de mercadorias que possuem referências de tempos passados. Atrelado a isso o esporte passa a se articular com os novos padrões de consumo da indústria do entretenimento, em que o futebol é cada vez mais utilizado como um espetáculo pela mídia. Suas próprias características, o aumento do poder de difusão dos meios de comunicação e o grande interesse do público propiciaram essa transformação não apenas do futebol, mas do esporte como um espetáculo de massa.

O esporte já era considerado um fenômeno cultural espalhado por vários pontos do planeta e praticado por diversas classes sociais antes da Segunda Guerra Mundial, mas somente "com a difusão da televisão e o desenvolvimento da cultura de massa que a lógica do mercado invadiria definitivamente a organização esportiva" (PRONI, 1998 , p. 69). No processo de espetacularização o esporte não é apenas um jogo, no qual indivíduos ou grupos estão engajados, mas sim algo a ser vendido a espectadores. Assim, o esporte adotou linguagem visual para atender à televisão e fotografias jornalísticas, inseriu publicidades em suas transmissões ao vivo e até mesmo alterou algumas regras para que o esporte fosse mais atraente ao espectador ou mais adequado à grade de programação da televisão. Como exemplo lembramos a alteração no sistema de pontuação do vôlei para o rally de 25 pontos, excluindo a vantagem, o que limitou o jogo ao tempo de 90-110 minutos; ou o fato de os jogadores de futebol serem proibidos de tirar a camisa na comemoração do gol para que o patrocinador fique em evidência e são punidos com cartão amarelo caso o façam. O esporte-espetáculo organiza-se levando em conta os valores econômicos vigentes. Portanto, no futebol, como atração rentável e bastante disseminada pelo planeta, a transformação dos torcedores em consumidores é algo natural, assim como o surgimento de uma gama variada de produtos esportivos para saciar os anseios de quem está ligado à modalidade.

As camisas retrô, o merchandising trazendo glórias do passado de clubes, ídolos que marcaram história e muitos produtos que navegam na onda da nostalgia é algo cada vez mais popularizado 
atualmente. Este tipo de consumo simbólico do passado está presente não apenas no futebol, mas também em várias outras áreas, como na produção cultural e seus filmes, séries de TV, além do retorno de produtos do passado, como o vinil.

Assim, o objetivo deste artigo é identificar como os elementos do passado e os sentimentos nostálgicos foram utilizados em duas camisas e duas campanhas publicitárias, do Flamengo e do Palmeiras, voltadas para os torcedores desses clubes. Para atingir esse objetivo usamos o método qualitativo exploratório. A pesquisa qualitativa possui caráter descritivo, sendo o processo o principal foco da abordagem, enquanto a pesquisa exploratória visa proporcionar ao pesquisador mais informações sobre o assunto, para que esse possa formular hipóteses.

Para esta análise, o presente trabalho foi dividido em três partes: primeiro será analisado o consumo simbólico como resultado das transformações do capitalismo e a consequente chegada ao futebol com sua espetacularização na sociedade de consumo. Em seguida, será analisado o fenômeno da nostalgia e os autores que o estudaram nos últimos anos para em seguida fazer o diagnóstico dos produtos com apelo à memória do passado que são: a terceira camisa do Palmeiras para o ano de 2019 e a campanha audiovisual produzida para lançála; uma camisa retrô do Flamengo e a peça publicitária feita pelo Flamengo para publicizar o programa sócio torcedor do clube, utilizando imagens saudosistas de conquistas e ídolos.

\section{Espetacularização do futebol e consumo simbólico}

A união entre mídia e consumo tornou-se algo intrínseco à sociedade atual podendo ser notada no contexto social, econômico e político. Andrews (1999) explica que as transformações do sistema capitalista e as novas indústrias culturais formadas pela tríade mídia, publicidade e marketing junto à informação, o grande produto dos tempos atuais, têm maior relevância sobre a antiga forma de manufatura industrial. Atualmente, os valores simbólicos, ou seja, os significados que determinado produto recebe são o que estimulam a economia.

Neste aspecto Rowe (1999, p. 74) coloca o termo "culturalização da economia" para explicar que nos tempos atuais uma mercadoria para ser vendida como diferenciada precisa agregar valores simbólicos e assim atrair consumidores e atenção.

No consumismo moderno, a atividade fundamental não é meramente a escolha, a compra e a utilização de um determinado produto, mas "a procura do prazer imaginativo a que a imagem do produto se empresta" (CAMPBELL, 2001, p. 299). Para Campbell, o consumo verdadeiro é o resultado desta procura pelo prazer quando 
se deseja não apenas um produto habitual e sim uma aquisição que possa proporcionar um prazer idealizado.

O que importa é que a apresentação de um produto como
"novo" permite ao consumidor em potencial ligar a este um
pouco do prazer de seu sonho, associando,
consequentemente, a aquisição e o uso do objeto à
compreensão do sonho. Tão logo ocorra essa identificação, o
produto será "desejado", como algo desse intenso anseio
gerado pela prática do devaneio passa a se vincular ao produto
em pauta. A prática visível do consumo, portanto, não é mais
do que uma pequena parte de um modelo complexo de
comportamento hedonista, cuja maior parte se dá na
imaginação do consumidor (CAMPBELL, 2001, p. 131).

Neste contexto, como uma das modalidades mais praticadas no mundo, o futebol tem se tornado cada vez mais mercantilizado e midiatizado. Essas duas palavras, juntamente com a espetacularização, formam uma tríade que explica a maneira como está organizado o atual futebol profissional de alto rendimento.

Como uma forma de entender o fenômeno da espetacularização na sociedade contemporânea, Kellner (2006, p. 5), define os espetáculos como:

[...] aqueles fenômenos de cultura da mídia que representam os valores básicos da sociedade contemporânea, determinam o comportamento dos indivíduos e dramatizam suas controvérsias e lutas, tanto quanto seus modelos para a solução de conflitos.

Kellner (2006) recorda também que a ideia de espetáculo está situada diante de uma estrutura capitalista que visa o crescimento e lucro através da transformação de tudo em mercadorias, bem como do controle do lazer e entretenimento. O espetáculo explica uma variedade de fenômenos, numa sociedade voltada para o consumo atrelado ao apelo midiático.

Em um momento em que a mídia é parte intrínseca do cotidiano das pessoas, no mundo do entretenimento, os espetáculos devem ser cada vez mais sedutores para atrair a atenção. $O$ esporte de alto rendimento e profissionalizado virou um dos principais produtos do espetáculo da cultura da mídia. "Tudo aliado à sociedade do consumo que acabou por unir forças com a comunicação de massa organizada através da produção e difusão de sons, imagens e informações" (PRONI, 1998, p. 86).

Rowe (1999) explica que o esporte como um todo se apresenta como um bem cultural institucionalizado servindo ao espetáculo e ao lucro, enquanto Ramirez Gallegos (2003, p. 110, tradução nossa) demonstra que é justamente a capacidade de ritualização que possui o futebol que o faz servir tão bem como um espetáculo, pois a 
modalidade tem condições de "emitir e receber mensagens, criar símbolos e condensar emoções". ${ }^{1}$

Para Alvito (2006), no atual mundo globalizado, o futebol atravessa divisões e fronteiras. Este esporte acaba por se assumir como uma mercadoria amplamente maleável ao permitir ser vendido em diferentes formas, como:

[...] na TV, no telemóvel (novo e promissor mercado), jogos eletrônicos de diversos tipos (inclusive aqueles que simulam a «administração» da parte financeira dos times), revistas especializadas, álbuns de figurinhas, em sites com conteúdo exclusivo (partidas, gols, melhores momentos). Isto sem falar na enorme variedade de produtos que usam os clubes - agora transformados em marcas - e seus distintivos (ALVITO, 2006, p. 456).

Exemplo de como o futebol é maleável podendo ser mercantilizado por diversas maneiras é a utilização de ídolos esportivos para agregar valor a produtos colocados à venda. Tal característica está ligada ao conceito de "culturalização da economia" proposto por Rowe (1999), que obviamente pode ser utilizado em outras indústrias e modalidades esportivas.

Levando a discussão para o capitalismo, Andrews (1999) também faz considerações sobre o momento atual do futebol no contexto da sociedade contemporânea. Ao entender que a cultura esportiva foi dominada pelos ditames dos conglomerados transnacionais, o autor ressalta algumas características de como se organiza o esporte atual: franquias e ligas transformadas em corporações transnacionais como uma importante indústria do entretenimento, espetáculos esportivos manipulados pelos meios de comunicação, a busca por um público ideal para seus anunciantes, além de estrelas do esporte cada vez mais midiatizadas.

Obviamente que a espetacularização e mercantilização da modalidade acaba interferindo em outros aspectos mais importantes do jogo com impacto gigantesco no seu público. Apesar de não concordar que o fenômeno da mercantilização seja algo recente dentro do futebol, Dubal (2010) destaca que no momento há maximização dos lucros que é refletida principalmente na cultura do torcedor. Um fenômeno resultante do impacto na cultura do torcedor atual é a gentrificação no qual muitos estádios acabam vendo a substituição de uma tradicional base de fãs por um grupo majoritariamente de classe média e alta.

Santos (2015) entende que o desenvolvimento crescente de uma indústria no futebol acaba gerando o que ele chama de privatização do jogo. Giulianotti (2012) analisa o surgimento de vários tipos de torcedor ao confirmar mudanças na cultura do torcer produzindo

1 "(...) de emitir y recibir mensajes, crear símbolos y condensar emociones". 
vínculo através da força midiática dos ícones da modalidade, como Cristiano Ronaldo, Neymar e Messi, que angariaram novos torcedores para clubes transnacionais, como Real Madrid, Barcelona, Juventus, PSG e outros.

No fim dos anos 1990, Proni (1998) já mostrava algumas características da espetacularização do esporte que obviamente podem ser notadas no futebol atual. Entre algumas características estão o crescimento do consumo de artigos esportivos, o desenvolvimento do marketing especializado na divulgação de marcas através do esporte e o desenvolvimento do profissionalismo dos atletas e técnicos.

Atualmente essas características são configurações rotineiras totalmente intrínsecas ao espetáculo futebolístico. Desta maneira, o aumento do consumo de artigos esportivos está cada vez mais utilizando referenciais históricos como forma de agregar valor simbólico aos produtos da modalidade. Exemplos não faltam como o marketing de programas de sócio-torcedor que utilizam ídolos do passado, crescimento de sites especializados em camisas retrô, canecas, chaveiros e uma grande gama de objetos que lembram antigas glórias. É a história e os sentimentos de nostalgia como simbolismo para dar peso a determinado produto ou serviço.

\section{Nostalgia e o passado como produto do futebol}

A nostalgia é tema de estudo cada vez mais frequente em diversas áreas e, além disso, tem ganhado importância como um produto cultural dentro da sociedade de consumo contemporânea. Pesquisando o crescimento da nostalgia dentro da produção televisiva, Castellano e Meimaridis (2017) traçam uma linha histórica da concepção desse termo. As autoras demonstram que o surgimento da palavra está ligado a aspectos negativos, como patologia e uma estreita conexão com a guerra, mas foi se transformando de maneira completa, passando a se referir à memória, até ser estrategicamente utilizado pela indústria. Apesar de considerarem a nostalgia como uma categoria complexa Castellano e Maimaridis (p. 65) a consideram "uma estratégia de manejo do tempo em um contexto em que ele parece cada vez mais fugidio". Desta maneira o uso da nostalgia transforma o tempo e permite às pessoas retomarem momentos do passado.

Os avanços da tecnologia tornaram esse retorno mais fácil, pois os símbolos do passado estão amplamente disponíveis nos tempos atuais. O aparato tecnológico sofisticado se configura, segundo Leonel e Klein (2018), com um acervo de armazenamento de produções saudosistas possuindo uma grande quantidade de arquivos culturais remotos. Grainge (2000, p. 32; tradução nossa) também destaca que a revolução digital, e principalmente o vídeo, transformaram a 
"capacidade de acessar, circular e consumir o passado cultural ${ }^{2 "}$ e tiveram como resultado um impacto grande no envolvimento da sociedade atual com o passado.

Como um produto de grande rentabilidade, a mercantilização da nostalgia é algo presente na sociedade através de produtos que trazem tendências e design com modelos do passado. Com isso muitos conteúdos e produtos que trazem esse referencial histórico podem ser observados em expressões como "vintage" e "retrô" e em áreas específicas como a produção de cultura para televisão, games e filmes pode-se perceber expressões como "remakes" e "revivals".

Para muitos autores, essa explosão nostálgica vivida nesses tempos não pode ser vista apenas como um fenômeno de mercado, mas o retrato de uma consequência social e cultural totalmente presente na sociedade contemporânea. Pesquisadores afirmam que esse tipo de consumo tende a se popularizar em tempos de descontinuidade e ansiedade. Um desses autores é Jameson (1991), que critica o declínio ou bloqueio da historicidade no pós-modernismo, que foi substituído por um modelo nostálgico.

Davis (1979) também destaca que o crescimento da nostalgia é uma resposta ao anseio por uma espécie de continuidade e Andrews (1999) foca na ideia de descontinuidade da pós-modernidade. Ele concorda com Jameson (1991), ao observar a canibalização aleatória do passado como uma forma eficaz de constituir o presente em tempos de crise ontológica. $O$ presente que se encontra em crise se torna um momento aleatório que pode ter ou não relação com o passado ou com o futuro. Então a história continua como simulação.

\begin{abstract}
Ao tornar a história um vasto, porém aleatório, arquivo de eventos, estilos e ícones que podem ser apropriados em qualquer combinação ou sequência, a cultura comercial rompeu fatalmente a cronologia tradicional, levando à compressão do tempo. Como consequência, estamos enraizados em uma cultura do tempo presente que propagou uma "amnésia histórica" entre a população consumidora ${ }^{3}$ (ANDREWS, 1999, p. 78; tradução nossa).
\end{abstract}

Além desse retorno ao passado em produtos que emulam tradições, hábitos e objetos de outras épocas, uma das características mais notáveis é que essas narrativas nostálgicas criam uma imagem distorcida do passado como melhor que o presente. Elas funcionam como uma celebração romântica do passado e também para Castellano

\footnotetext{
2 Original: "ability to access, circulate, and consume the cultural past".

3 Original: "By rendering history a vast, yet random, archive of events, styles, and icons that can be appropriated in any combination or sequence, commercial culture has fatally disrupted traditional chronology, leading to the compression of time. As a consequence, we are ensconced in a culture of the present tense that has propagated a 'historical amnesia' among the consuming populace".
} 
e Meimaridis (2017), como uma espécie de evasão do consumidor para esquecer sua realidade atual.

Após analisar como a nostalgia tem sido utilizada na indústria do entretenimento para o consumo e seu crescimento na sociedade à medida que as novas tecnologias de áudio e vídeo foram evoluindo, o artigo irá trazer especificamente como a nostalgia tem sido incorporada a produtos relacionados aos clubes do futebol brasileiro como forma de abordar o passado, e por sua ligação com o conceito de memória.

\section{0 apelo à memória}

Quem foi o herói do último título de seu time? E quem fez o último gol na partida mais recente? Por que é mais fácil saber a resposta da primeira do que da segunda pergunta? A reposta passa pela memória e por como momentos e pessoas que são enaltecidos e ficam marcados na história de um clube de futebol, sendo relembrados de modo significativo.

De acordo com Le Goff (1990, p. 366) memória é a "propriedade de conservar certas informações", que nos remete a um conjunto de funções psíquicas através das quais podemos atualizar o passado. E a memória é importante exatamente por conta dessa capacidade de conservação e atualização do passado. Em marketing, a memória é utilizada para estimular o consumidor a olhar para o passado e desejar revivê-lo de algum modo. No futebol, as memórias são capazes de conectar-nos não somente ao time, mas fortalecem o sentimento de pertença ao relembrar relações significativas, e aqui o apelo ao passado e à memória pode ser visto na venda das camisas denominadas retrô. Tal estilo, originado na década de 1960, na França, inspira-se em um passado recente, uma releitura de épocas passadas retratada no momento.

Considerada como uma forma viva do pertencimento de um torcedor ao clube, a indústria percebeu possibilidades de grande rentabilidade com esses tipos de produtos, sendo as camisas retrô uma espécie de nicho com favorável aceitação do consumidor. Além disso, a ebulição de elementos retrô fez com que a publicidade também se valesse de sua materialidade. Essas materialidades discursivas têm frequentemente valores positivos (algo que já deu certo), trazendo uma viagem ao passado da memória coletiva.

Halbwachs (1990, p. 2) entende que a memória coletiva é "o processo social de reconstrução o passado vivido e experimentado por um determinado grupo, comunidade ou sociedade"; ou seja, é um campo aberto a proposições dos sujeitos com tentativas de definição e reforço do sentimento de pertença com aquilo que o grupo acredita ser oportuno compartilhar.

Dessa forma, essas camisas retrô possuem a mesma estética das encontradas em algum ano ou época passada geralmente com o intuito 
de relembrar momentos vitoriosos e históricos do clube, além de jogadores marcantes ainda admirados no contexto atual. As propagandas desses produtos também tendem a enfatizar esse contexto ao relembrar um passado vitorioso, com o objetivo de elevar o conceito nostálgico para os torcedores-consumidores.

Todo esse processo publicitário de retorno ao passado mostra, de algum modo, que algo se traz de volta e algo se esquece, visto que há um recorte. Sempre se destaca algo que possa comover, alimentar a nostalgia, vender. (CARVALHO; FURLANETTO, 2015, p. 205).

Castellano e Meimaridis (2017) afirmam que os produtos nostálgicos transformam-se em uma espécie de celebração romântica do passado e pode até, dependendo da situação atual do clube de futebol, funcionar como uma espécie de evasão do consumidor para esquecer uma possível realidade momentânea, o que se traz do passado passa por um processo de seletividade e esquecimento.

O primeiro produto a ser analisado é a terceira camisa usada pelo Palmeiras, na temporada de 2019. Trata-se da releitura da camisa usada pelo goleiro Marcos, da marca Puma, quando da conquista da Copa Libertadores da América. Assim, um ídolo do clube ganha valor simbólico pela nostalgia de um passado que precisa ser rememorado em uma mercadoria nova. Vemos, então, o estímulo à memória coletiva através de fatos da ordem dos grandes acontecimentos (vitória que entrou para a história do clube). Isso cria um halo em torno da camisa usada pelo ídolo do Palmeiras naquele momento, simulando o retorno ao passado e à força da memória.

A campanha publicitária - Comercial Puma com Marcos (2019), produzida para lançar a camisa também utiliza a imagem do goleiro que empresta ao produto boa parte da carga simbólica de um ídolo midiático, além da nostalgia, que precisa para ser considerada especial para o torcedor palmeirense. No peça Marcos enfatiza o quanto aquela camisa foi importante para que ele se transformasse no ídolo da torcida: "Essa camisa significa muito para mim [...], foi com ela que eu me tornei o Marcos, conhecido pelo palmeirense e chamado de Santo. Dá para dizer tranquilamente que essa camisa mudou a minha vida". Essa é também uma das características do futebol mercantilizado e espetacularizado em que as estrelas do esporte estão cada vez mais midiatizadas e são utilizadas para agregar valor simbólico aos novos produtos no mercado. Essa não é apenas a camisa usada em um momento de glória, por um dos jogadores mais importantes do time, mas é também a camisa que o consagra enquanto ídolo, peso dado pelo próprio goleiro em sua fala na campanha publicitária.

Os produtos que revivem o passado extraem os recursos de design, artefatos e até as experiências que são agradáveis esquecendo 
as que não são. Desta forma em vários aspectos eles são melhores do que os do passado. Assim, é importante observar que esse produto novo possui apenas o design de determinado passado rememorado, porém são utilizadas tecnologias modernas para produzir o objeto. É o que Andrews (1999, p. 81) analisa como "nostalgia de alta tecnologia, em que elementos tradicionais são retirados de determinados períodos históricos e usados com tecnologia de ponta; ou como Retrô pele, que de acordo com Carvalho e Furlanetto (2015, p. 219), a "manifestação retrô está na composição de um produto inovado, tecnologicamente falando, mas imitando traços de um antigo". O uso de alta tecnologia é justificado, uma vez que a camisa foi utilizada pelos jogadores na temporada de 2019.

Mas há casos que além do design, o produto também é fabricado conforme técnicas antigas ou utilizando material da época, como o caso da camisa da linha retrô que relembra Zico, maior ídolo do Flamengo e também a conquista do tricampeonato carioca no final dos anos 1970. Conforme consta em sites de venda do produto, a camisa têm o símbolo retrô do time bordado e a assinatura do ex-jogador Zico; a gola é em $\mathrm{V}$ e o punho das mangas vem com acabamento canelado para melhor ajuste ao corpo e por fim, nas costas, o número do craque complementa a peça.

A camisa não é apenas uma peça do vestuário, mas uma forma de os torcedores vestirem seu amor pela história do time. O futebol, para Damatta (1994), é um campo de vitórias e derrotas cíclicas, um local onde se trava uma eterna luta agonística por status, onde as torcidas se alternam em posições superiores ou inferiores. O momento da vitória é marcado pela exibição da camisa do time. Assim, a camisa do Flamengo analisada não só congela no tempo um momento de glória que pode ser rememorado e re-comemorado, mas traz também, além do número 10 consagrado por Zico no clube, sua assinatura para incrementar o valor nostálgico da camisa e estabelecer a relação entre a memória de um ídolo do futebol nacional e o Flamengo.

Este fenômeno da força midiática do ícone esportivo foi comentado por Giulianotti (2012) e se percebe perfeitamente como um ídolo pode ser também usado para agregar valores a uma mercadoria. Aqui, assim como na camisa palmeirense, o ídolo midiatizado é usado para adicionar simbolismo à camisa, além de toda a carga nostálgica que o produto traz ao manejar o tempo trazendo de volta toda a carga emotiva de um período que foi importante para os torcedores dos dois clubes.

Como o produto da análise anterior é notável que esta camisa do Flamengo possua o design característico de um recorte específico do passado que junto à referência de um ídolo relembra o período da sequência de títulos do campeonato estadual.

Além das camisas outra forma muito comum encontrada de apelo ao passado e à memória da nostalgia do torcedor é vista em 
propagandas para sócios veiculadas recentemente pelos clubes brasileiros. Para chamar atenção dos novos consumidores, estas peças publicitárias usam imagens do passado, das glórias, das tradições e dos ídolos.

Leonel e Klein (2018), Castellano e Meimaridis (2017) e Grainge (2000) deixaram claro como a revolução digital, principalmente o vídeo, recurso que é utilizado nas duas campanhas publicitárias analisadas, transformaram a forma com que a sociedade pode se relacionar com o passado. É possível notar que não apenas o futebol, seus signos, símbolos e ídolos são espetacularizados como também a nostalgia em todos os exemplos citados.

Voltando ao objeto de análise, o Flamengo com a campanha de 2017, com foco no pertencimento do flamenguista com o conceito "Isso aqui é Flamengo", da Nova Campanha de sócio-torcedor do Flamengo (2017). A intenção com a peça publicitária era chamar atenção para os programas especiais de sócio voltados para o torcedor do clube, residente ou não no Rio de Janeiro.

Evocando imagens que remetem ao título mundial conquistado, em 1981, no Japão sobre o Liverpool, apresenta também a taça da respectiva conquista e comemorações da própria torcida no Maracanã. O narrador afirma: "Isso não é uma conquista de campeonato, é o mundo se curvando a uma geração", que gera sentimentos nostálgicos do torcedor flamenguista. A imagem do jogador de futebol Zico, em tempos passados, com a camisa de número 10 que referencia o craque - conforme já mencionado - bem como nos tempos atuais, sentado em uma espécie de trono ladeado por dois urubus (mascote do Flamengo) e a voz que diz: "A gente não tem ídolo, tem uma entidade", denota o cuidado de gestores ao escolher referências do passado no processo de construção da identidade do flamenguista.

Esses segmentos aliados à narração, que ainda apontam que a camisa é o manto sagrado, a torcida é uma nação e termina dizendo "Isso aqui não é um clube, isso aqui é o Flamengo", além de fortalecer uma identidade de pertencimento a algo além da vida cotidiana, excepcional, vai ao encontro do desejo por autenticidade do torcedor na cultura de consumo. Assim, vemos o relançamento moderno do passado e a construção da tradição.

Tradições e costumes, crenças e expectativas constituem hoje recursos adaptáveis, flexíveis, plásticos, numa sociedade cosmopolita de culturas e estilos de vida intercruzados. Portanto, o mundo moderno não implica na morte da tradição. Em vez disso, situa e contextualiza as tradições como contextos de tomada de decisões e como fontes alternativas de conhecimentos, valor e moralidade. Se antes vivíamos num mundo tradicional, hoje vivemos num mundo de tradições (KOWALSKI, 2003, p. 361). 
Dessa forma, literatos, jornalistas, cronistas, poetas e torcedores associaram ao Flamengo a "moralidade, religiosidade, atos (de violência ou não), costumes, modelos normativos e organizacionais singulares, ideais de honra e de nacionalismo, identidade, lealdade e paixão $[\ldots]$, refletindo no caráter de formação de uma comunidade [...]" (KOWALSKI, 2003, p. 369).

\section{Considerações finais}

Dentro dos objetos analisados, notamos a presença do trabalho de marketing especializado na divulgação de marcas com o esporte. São empresas que entenderam Flamengo e Palmeiras como uma marca em potencial e que possuíam especificidades próprias que foram usadas para atrair o torcedor-consumidor. Esse aspecto foi destacado por Proni (1998) e vem desde o fim dos anos 1990 como parte da espetacularização do esporte, além do crescimento do consumo de artigos esportivos.

$\mathrm{O}$ apelo à memória, às imagens de um recorte específico do passado, além da presença constante de ídolos de outros tempos é o que nestes objetos dão um valor simbólico significativo para o consumidor e que estão definitivamente presentes em cada uma destas mercadorias.

É importante notar que estes são aspectos claros de que a transformação dos torcedores em consumidores é algo natural dentro desse contexto em que o futebol se encontra. As características de espetacularização e mercantilização caminham juntas dentro do esporte de alto rendimento com o surgimento de uma ampla gama de produtos esportivos. O nicho nostálgico das camisas retrô é apenas mais um segmento que é reflexo deste momento.

O objetivo deste artigo foi identificar como os elementos do passado e os sentimentos nostálgicos foram utilizados em duas camisas retrô e duas campanhas publicitárias, de Flamengo e Palmeiras. O que percebemos foi como as novas práticas e transformações na maneira de consumir trouxeram o simbolismo como forma de gerar interesse em novos produtos. Nos casos analisados ficou demonstrado como ocorre, na prática, o apelo ao passado em produtos relacionados com este esporte.

A espetacularização desta modalidade é um processo totalmente atrelado à comunicação de massa. Assim, o futebol possui características excelentes para se adaptar como um dos principais produtos do espetáculo da cultura midiática e como consequência isso vem fomentando sua utilização para a venda de uma gama cada vez maior de produtos esportivos.

Chegando ao campo da nostalgia e sua maior utilização como valor de consumo nos produtos esportivos e em outras áreas do entretenimento, este estudo não teve como intenção fechar o tema até 
porque seria necessário um trabalho mais longo para isso. Ao trazer autores como Andrews (1999) e Jameson (1991) que possuem uma visão bastante crítica da utilização de referências do passado se destaca o fato de que os elementos nostálgicos podem ser frutos de anseios da sociedade descontente com seu presente. Contudo, se busca também trazer um contraponto com autores como Grainge (2000, p. 29; tradução nossa) que afirma que essa crescente necessidade de apelo à memória e ao passado pode ser apenas "o resultado de transformações tecnológicas específicas e estratégias de marketing de nicho"4.

Ao juntar esses autores se busca fazer uma articulação de suas ideias que são perfeitamente ajustáveis ao tentar compor esse cenário de entendimento do crescimento da nostalgia que também chegou ao futebol. Não se pode incorrer no risco de entrar num cenário apenas apocalíptico reduzindo o consumo nostálgico das camisas retrô, por exemplo, apenas na ansiedade e insatisfações das pessoas com 0 presente.

Os produtos analisados neste artigo mostram que o fenômeno da nostalgia chegou ao futebol como um nicho de mercado bastante rentável, fruto também da grande mercantilização e utilização deste esporte como uma indústria do entretenimento valiosa o que propicia assim o aumento do consumo esportivo.

Relembrar títulos, um passado vencedor de um período específico ou um ídolo do passado são características notadas em todos os produtos trazidos para análise, seja em uma camisa com design dos anos 1970 e 1990, ou uma peça publicitária voltada para os sóciotorcedores destes clubes. Assim como em outros produtos culturais que trazem características históricas é possível entender que o passado acaba reconfigurado para os tempos atuais respeitando as dinâmicas específicas do presente em que foi desenvolvido. $O$ resgate do passado via principalmente o lançamento de camisas retrô e o uso da imagem e do valor de ídolos dos clubes, simula o sentimento de um acontecimento do passado romantizando-o.

Assim, pode-se perceber que relembrar um passado romantizado tem sido cada vez mais um ótimo negócio e não somente dentro do futebol, mas em vários outros setores da indústria do entretenimento, em que a publicidade também tem um papel fundamental.

\footnotetext{
4 Original: "[...] the result of specific technological transformations and strategies of niche marketing".
} 


\section{Referências}

ALVITO, Marcos. A parte que te cabe neste latifúndio: o futebol brasileiro e a globalização. Análise Social, Lisboa, v. 41, n. 179, p. 451-474, 2006.

ANDREWS, David L. Dead and alive?: Sports history in the late capitalist moment. Sporting Traditions, Australian, v. 16, n. 1, p. 73-84, 1999.

\section{CAMPBELL, Colin. A ética romantica e o espírito do consumismo} moderno. Rio de Janeiro: Rocco, 2001.

CARVALHO, Richarles S. de; FURLANETTO, Maria M. Memória, Nostalgia e Publicidade: O caso das camisas retrô de futebol. Casa: cadernos de Semiótica Aplicada, Araraquara, v. 13, n. 1, p. 189-225, 2015.

CASTELLANO, Maika; MEIMARIDIS, Melina. Produção televisiva e instrumentalização da nostalgia: o caso Netflix. Revista GEMInIS, São Carlos, v. 8, n. 1, p. 60-86, 2017.

COMERCIAL PUMA COM MARCOS. 2019. Disponível em: https://www.youtube.com/watch?v=cpTuihfz-wY\&feature=emb_logo. Acesso em: 22 jun. 2019.

DAMATTA, Roberto. Antropologia do óbvio: notas em torno do significado social do futebol brasileiro. Revista USP (Dossiê Futebol), São Paulo, n. 22, p. 10-17, 1994. Disponível em:

http://www.revistas.usp.br/revusp/article/view/26954/28732. Acesso em: 22 jun. 2019

DAVIS, Fred. Yearning for yesterday: a sociology of nostalgia. New York: Free Press, 1979.

DUBAL, Sam. The neoliberalization of football: Rethinking neoliberalism through the commercialization of the beautiful game. International Review for the Sociology of Sport, [S. L.], v. 45, n. 2, p. 123-146, 2010.

RAMIREZ GALLEGOS, Jacques Paul. Fútbol e identidad regional en Ecuador. In: RAMIREZ GALLEGOS, Jacques Paul. Futbologias: futbol, identidad y violencia en America Latina. Buenos Aires: CLACSO, Consejo Latinoamericano de Ciencias Sociales, 2003. p. 101-121, 2003. Disponível em: http://biblioteca.clacso.edu.ar/clacso/gt/20100920125614/7PIIRGallegos.pdf. Acesso em: 22 jun. 2019.

GIULIANOTTI, Richard. Fanáticos, seguidores, fãs e flâneurs: uma taxonomia de identidades do torcedor no futebol. Recorde: Revista de História do Esporte, Rio de Janeiro, v. 5, n. 1, p. 1-35, 2012.

GRAINGE, Paul. Nostalgia and style in retro America: moods, modes and media recycling. Journal of American Culture, [S. L.], v. 23, n. 1, p. 2734, 2000.

HALBWACHS, Maurice. Memória coletiva. São Paulo: Vértice, 1990.

JAMESON, Frederic. Postmodernism, or, the cultural logic of late capitalism. Durham: Duke University Press, 1991. 
KELLNER, Douglas. A cultura da mídia e o triunfo do espetáculo. [Tradução: Rosemary Duarte]. Líbero, São Paulo, ano VI, v. 6, n. 11, p. 4-15, 2006. KOWALSKI, Marizabel. Por que Flamengo? Rio de Janeiro: Gama Filho, 2003.

LE GOFF, Jacques. História e memória. Campinas, São Paulo: UNICAMP, 1990.

LEONEL, Bruno; KLEIN, Alberto A. A mídia nostálgica e a digitalização do passado na comunicação de massa. In: CONGRESSO BRASILEIRO DE CIÊNCIAS DA COMUNICAÇÃO, 41., Joinville, 2018. Anais [...]. São Paulo: Intercom, 2018. p. 1-12.

NOVA CAMPANHA DE SÓCIO-TORCEDORDO FLAMENGO. 2017. Disponível em: https://www.youtube.com/watch?v=3_KqqEdf1Xk. Acesso em: 22 jun. 2019.

PRONI, Marcelo W. Esporte-espetáculo e futebol-empresa. 1998. 262 f. Tese (Doutorado em Educação Física) - Faculdade de Educação Física da Universidade Estadual de Campinas, Campinas, 1998.

ROWE, David. Sport, culture and the media: the unruly trinity. Buckingham: Open University Press, 1999.

SANTOS, Irlan S. O futuro da torcida: midiatização, mercantilização do futebol e resistência torcedora. In: CONGRESSO BRASILEIRO DE CIÊNCIAS DA COMUNICAÇÃO, 38., Rio de Janeiro, 2015. Anais [...]. São Paulo: Intercom, 2015. p. 1-15. 